\title{
Ultrasonographic Diagnosis of Ileal Intussusception in Calf
}

\author{
Ana Clara Sarzedas Ribeiro ${ }^{1}$, Rodolfo José Cavalcanti Souto ${ }^{2}$, Tayrlla Polessa Rodrigues Silva ${ }^{1}$, \\ José Augusto Bastos Afonso ${ }^{2}$, Carla Lopes de Mendonça ${ }_{\odot}^{2}$, Nivaldo de Azevedo Costa ${ }^{2}$, \\ Luiz Teles Coutinho ${ }^{2}$ \& Jobson Filipe de Paula Cajueiro ${ }^{2}$
}

\begin{abstract}
Background: Intussusception, characterized by invagination of an intestinal segment into the lumen of the adjacent segment, is one of the main causes of intestinal obstruction in cattle, and occurs more frequently in calves. The diagnosis of the disease is based on the history, clinical examination, and complementary exams, which are a challenge in this species, especially in calves, in which transrectal palpation is limited. As it is a non-invasive, effective, and low-cost test, ultrasonography could be an important tool in the diagnosis of intestinal obstructions, in which time is essential for the prognosis. Therefore, the objective was to report a case of intussusception in a calf diagnosed by ultrasound.

Case: A 4-month-old calf, weaned at 3 months and raised intensively, was treated at the Clínica de Bovinos de Garanhuns, campus of the Universidade Federal Rural de Pernambuco (CBG/UFRPE), with a history of apathy, anorexia, and dyschezia for 3 days. On physical examination, fever, moderate dehydration, tachycardia, tachypnea with polypnea, bilaterally bulging abdomen, sound of fluid on ballottement, ruminal and intestinal hypomotility, and melena were observed. The hematological findings revealed leukocytosis due to neutrophilia (degenerate neutrophils), hypoproteinemia, and hyperfibrinogenemia. The analysis of the ruminal fluid showed compromised microbiota and increased chloride content. The transabdominal ultrasonography demonstrated, in the right ventral region, hypermotile and full small bowel loops and an increase in the volume of the peritoneal fluid. In addition, there was a segment of the small intestine which, in cross-section, showed multiple concentric rings ("onion rings", "target pattern", or "bull's eye") and adherence to adjacent loops, compatible with intestinal obstruction due to intussusception. Due to the seriousness of the clinical condition and the ultrasound findings, the animal was euthanized and the necropsy revealed focal fibrinous peritonitis and intestinal obstruction due to intussusception in ileum intestinal segments.

Discussion: Intussusception has previously been reported in calves, however this is the first report of ultrasound diagnosis of the disease in Brazil. Although the etiology is rarely confirmed, the age group and recent changes in diet (weaning) were predisposing factors. The history, clinical signs, and laboratory tests were similar to those described in cattle with intussusception, however they may be present in other gastrointestinal illnesses. Other authors have also reported that the nonspecificity of the signs and the impossibility of performing transrectal palpation made it difficult to diagnose intestinal obstruction in calves without the use of other diagnostic tools. As it is a non-invasive and accurate technique, ultrasound has been used in ruminants for diagnostic purposes, including intestinal obstructions. In the present case, the main findings are described as the presence of a lesion with the appearance of multiple concentric rings, hypermotile, dilated, and full intestinal loops. The pathological findings were compatible with the ultrasound images and similar to those described by other authors, confirming the diagnosis. The use of ultrasonography as a diagnostic tool in cattle should be expanded, aiming at the early determination of diagnosis and prognosis, to reduce producer costs and animal discomfort. In cases of intussusception, late diagnosis makes treatment unfeasible.
\end{abstract}

Keywords: cattle, diagnostic imaging, intestinal obstruction, ultrasound. 


\section{INTRODUCTION}

Intussusception is one of the most important causes of intestinal obstruction in cattle, occurring in animals of all ages. It is characterized by invagination of an intestinal segment into the lumen of the adjacent segment, where the invaginated part is denominated intussusceptus and the invaginant part intussuscipient. The pathogenesis involves hyperperistalsis in the oral intestinal segment to obstruction, associated with relaxation of the aboral segment. The primary cause of this disease is generally unknown, but any focal disturbance of intestinal motility can favor its occurrence. Sudden alterations in diet, viral and bacterial enteritis, intestinal parasitism, mural or intramural lesions such as neoplasms, granulomas, abscesses, hematomas, foreign bodies, and drugs that affect intestinal motility have been identified as predisposing factors $[1,9,22]$.

The diagnosis of intestinal obstruction is a challenge for the buiatrics, especially in calves, in which transrectal palpation is limited. The history, clinical and laboratory findings, imaging tests, and exploratory laparotomy should be considered [2]. As it is a non-invasive, effective, and low-cost diagnostic method, the use of ultrasonography should be expanded in ruminant internal medicine [5], as it can be an important tool in cases of intussusception, allowing the early establishment of the diagnosis and prognosis of the disease. Since there are no reports on the use of ultrasonography in the diagnosis of intussusception in young cattle in Brazil, this study aimed to highlight the imaging findings, as well as clinical, laboratory, and anatomopathological findings of a four-month-old calf diagnosed with intussusception.

\section{CASE}

A four-month-old Holstein male bovine was treated at the Clínica de Bovinos de Garanhuns, campus of the Universidade Federal Rural de Pernambuco (CBG/UFRPE), with a history of apathy, anorexia, and dyschezia for three days. According to the owner, the animal had been weaned approximately 30 days previously and was raised intensively, receiving a diet based on forage cactus (Opuntia spp.), corn silage, and mineral salt ad libitum.

The physical examination of the animal showed a temperature of $39.3^{\circ} \mathrm{C}$, moderate dehydration (8\%), tachycardia (112 bpm), tachypnea (52 mrpm) with polypnea, bilaterally bulging abdomen, sound of fluid when the right ventral-abdominal region ballottement, ruminal and intestinal hypomotility, and a small amount of blackened and oily stools (melena) (Figure 1).

A blood sample was collected by jugular venipuncture for hematological tests [12], which revealed leukocytosis $(12,950 / \mu \mathrm{L})$ due to neutrophilia $(8,547 / \mu \mathrm{L})$, hypoproteinemia $(6.2 \mathrm{~g} / \mathrm{dL})$, and hyperfibrinogenemia ( $800 \mathrm{mg} / \mathrm{dL})$. Ruminal fluid was collected with the aid of an orogastric tube, and the examination revealed compromised microbiota and increased chloride content (52.34 mmol/L) [10]. The peritoneal fluid collection was unsuccessful, probably due to the inflammatory alteration being restricted to the intestinal recess.

During the transabdominal ultrasound in the right ventral region, using a B-mode device, with a convex transducer at a frequency of $5 \mathrm{MHz}$ (Mindray ${ }^{\circledR}$ Z6 Vet) ${ }^{1}$ hypermotilic small bowel loops were observed, $\geq 3 \mathrm{~cm}$ in diameter, filled with echogenic and heterogeneous content, with hyperechoic spots, and an anechoic image between the loops, suggesting an increase in peritoneal fluid volume (Figure 2). Ventrally to the ninth right intercostal space, a cross-section of the intestinal loop measuring $7.7 \mathrm{~cm} \times 5.2 \mathrm{~cm}$ was evidenced, with the appearance of multiple concentric rings ("onion rings", "target pattern", or "bull's eye"), delimited by a hyperechoic outer ring (intussuscipient wall) around a hypoechoic area and a highly reflective inner ring (intussusceptum wall) with an anechoic center (intestinal lumen) [Figure 3]. Adherence was also found between the intussuscipient segment and adjacent loops, characterized by indistinctness between the limits of the loop walls and deposition of hyperechoic and heterogeneous material adhering to

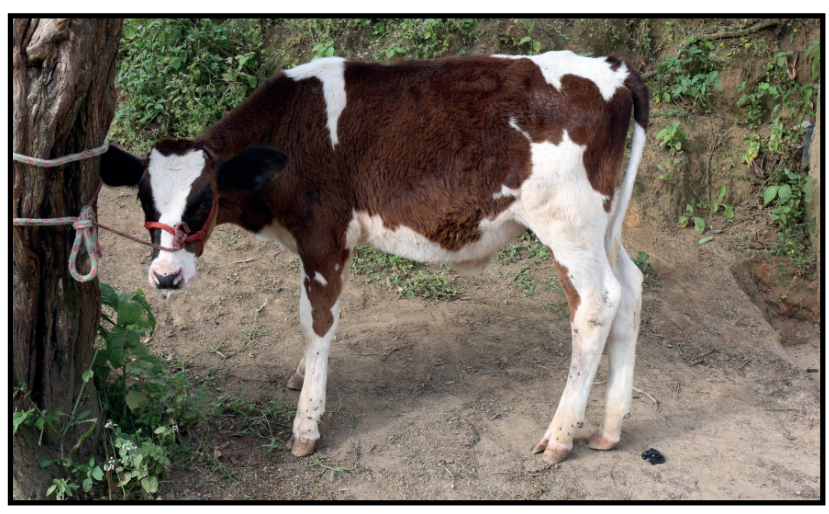

Figure 1. A 4-month-old male calf at the initial clinical examination, showing apathy, bilaterally bulging of the abdomen, and blackened, oily stools (melena). [Fonte: CBG-UFRPE, Campus de Garanhuns]. 


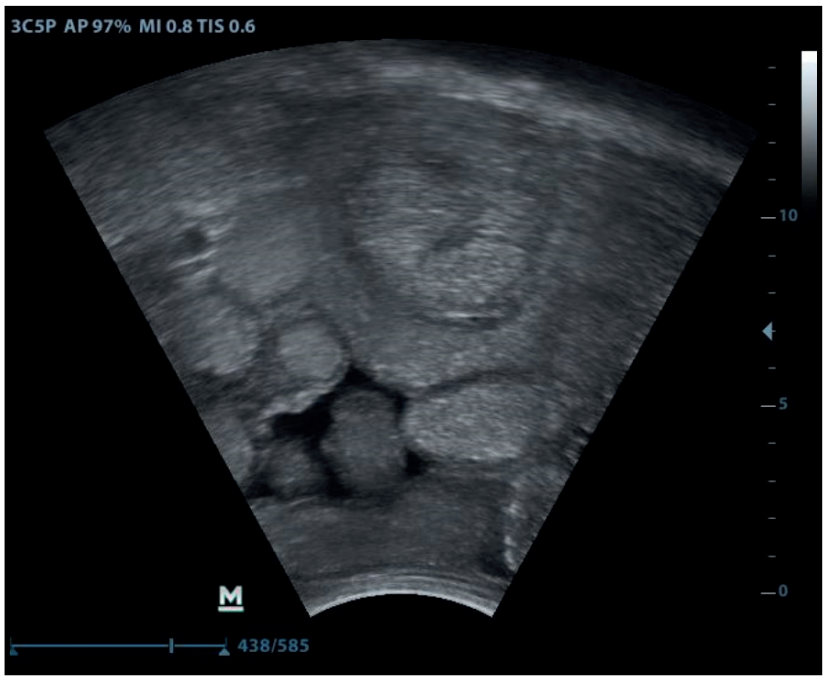

Figure 2. Transabdominal ultrasound in bovine in the right ventral region Ultrasonographic image of dilated small bowel loops (diameter $\geq 3 \mathrm{~cm}$ ), filled with echogenic and heterogeneous content, with hyperechoic spots, and an anechoic image between the loops suggesting an increase in the volume of peritoneal fluid. [Fonte: CBG-UFRPE, Campus de Garanhuns].

these segments (Figure 3). Ultrasonographic images suggested intestinal obstruction due to intussusception and focal peritonitis.

Due to the seriousness of the clinical condition and the ultrasound findings, the animal was euthanized [16] and necropsied. Pathological examination revealed focal fibrinous peritonitis within the intestinal recess, where there was an intestinal obstruction due to intussusception, characterized by the presence of an invaginated ileum segment in the adjacent segment. The digestive tract was distended by food content orally to the obstruction and, empty aboral from it (Figure 4).
The affected intestinal portion showed edema, hyperemia, hemorrhages, and fibrin deposits on the mucous and serous surfaces. When cutting the ileum segment, oral to the obstruction, there were small mucosal ulcers.

\section{DISCUSSION}

Although intussusception in calves has also been reported by other authors $[19,22]$, there is no report of cases diagnosed by ultrasound in Brazil, this being the first. Intussusception is the cause of 26 to $28 \%$ of intestinal obstructions in cattle [18,22], which account for $9 \%$ of digestive tract diseases in ruminants [23]. Some studies report a higher frequency of the disease in calves under 2 months of age [8], however, unlike the present report, some authors who claim that there is no age predisposition to the occurrence of intussusception [20].

The causes of intussusception are rarely determined, however some predisposing factors can be identified. The occurrence in calves seems to be associated with factors such as dietary changes and a high incidence of viral, bacterial, and parasitic gastroenteritis, which cause disturbances in intestinal motility $[2,9,17]$. In the present case, in addition to the age range, the animal had been weaned and so had undergone recent changes in feeding, which probably led to intussusception.

The anamnesis and clinical signs were similar to those described by other authors in both calves and adult cattle [13,14,17,19,21,22]. Signs of colic were not observed as described in other cases, however it should

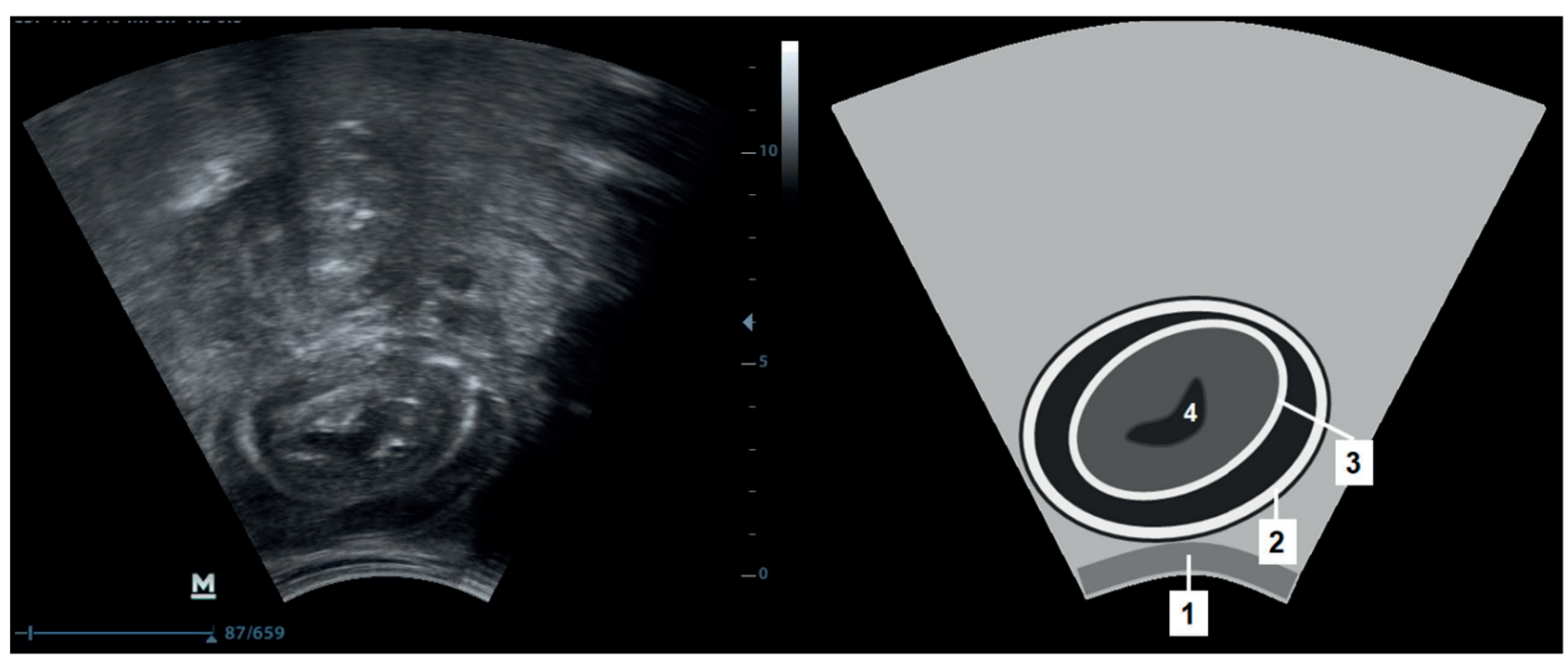

Figure 3. Ultrasonographic image of ileal intussusception in a bovine. Transabdominal ultrasound in the right ventral region. Cross-section of intestinal loop, with appearance of multiple concentric rings ("onion rings", "target pattern" or "bull's eye"). 1- abdominal wall; 2- intussusceptive wall; 3- intussusceptum wall; 4- intestinal lumen. [Fonte: CBG-UFRPE, Campus de Garanhuns]. 


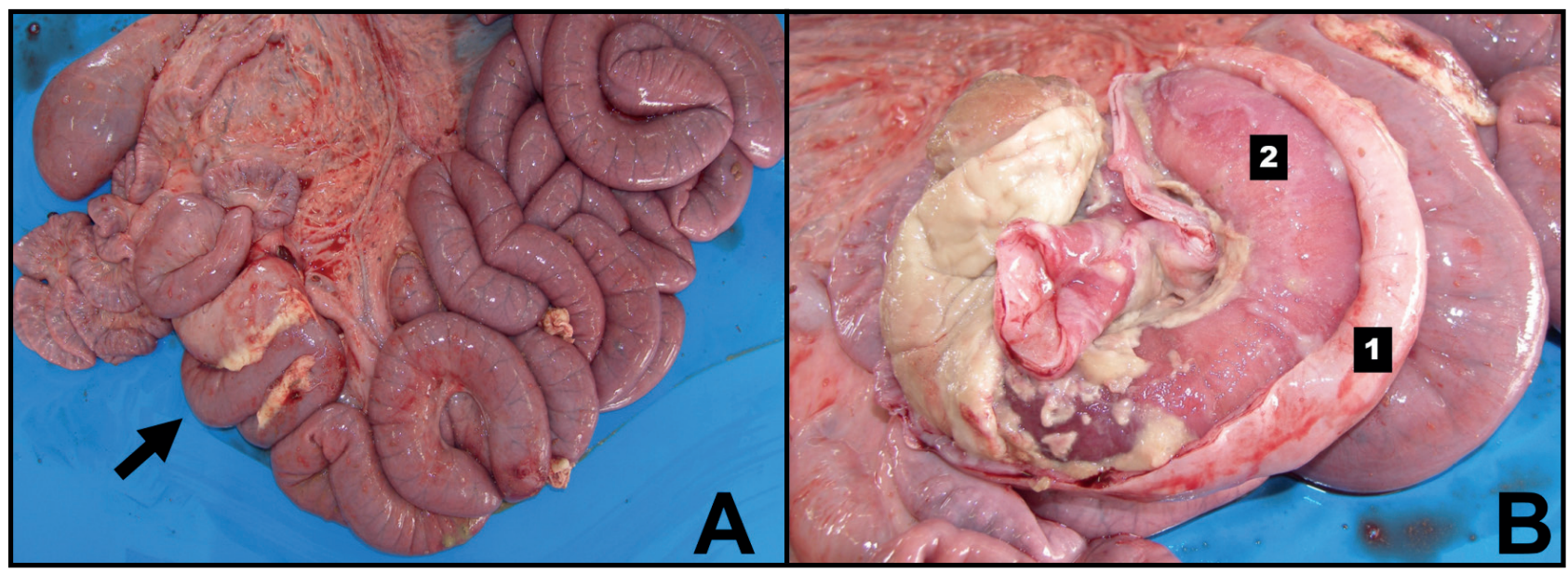

Figure 4. Anatomopathological exam in bovine. A- Intussusception in ileal segment (arrow), with adjacent focal fibrinous peritonitis, replete intestinal loops oral to the obstruction, and empty loops aboral to the obstruction. B- Intestinal segment invaginated into the lumen of the adjacent segment, with fibrinous material adhered to the serosa; 1- intussusceptive wall; 2- intussusceptum. [Fonte: CBG-UFRPE, Campus de Garanhuns].

be considered that the animal was referred to veterinary care only three days after the onset of symptoms. For some authors [2,9] these signs are observed mainly in the first $24 \mathrm{~h}$ of evolution, after this period the colic loses intensity and the animals present apathy, dehydration, anorexia, gastrointestinal hypomotility, and abdominal distension due to the accumulation of gases and fluids in the pre-stomachs and intestines, signs that were observed in the present case.

The dehydration observed may be a consequence of the accumulation of gastrointestinal secretions in the lumen of the intestine, associated with the inability of intestinal absorption due to inflammatory wall changes, as well as the reduction or absence of water intake by the animal. The increase in heart and respiratory rates were consequent to pain and circulatory alterations resulting from the intestinal injury $[2,9,17,22]$. The accumulation of fluid and gas in the small intestine and rumen promotes distension of these organs and, consequently, of the abdomen, in addition to inhibiting gastrointestinal motility [11]. Fecal production tends to be minimal or absent after $24 \mathrm{~h}$ of intestinal obstruction [9], however, the presence of small amounts of feces with melena characteristics can occur in up to $50 \%$ of affected animals, as observed in this case [22].

Laboratory exams were consistent with what is described in the literature $[1,15,19,22]$. An increase in the chloride content in the rumen fluid above $30 \mathrm{mEq} / \mathrm{L}$ is associated with the reflux of the abomasal content into the rumen, due to the interruption of the physiological flow of ingest due to intestinal obstruction [2,3].
The presence of leukocytosis due to neutrophilia and elevated plasma fibrinogen characterize the inflammatory process present in these cases. These hematological findings tend to worsen when there is ischemic necrosis of the affected intestinal segment, as well as in cases that present with peritonitis $[9,15,22]$.

It should be noted that although the epidemiological, clinical, and laboratory findings are compatible with what has been described for the disease, these same findings may be present in other gastrointestinal disorders, among which are jejunal hemorrhage syndrome, paralytic ileus, obstructions by foreign bodies, intestinal torsion, vagal syndrome, intestinal neoplasia, and abomasal ulcers, which should be considered in the differential diagnosis $[3,9]$.

The use of ultrasound as a diagnostic method in cattle has been described since the 1990s [6], however, in the last 15 years, there has been an increase in the use of this tool $[4,5,15,24]$. Since 2005 , the literature has indicated ultrasound as the diagnostic tool of choice for abdominal disorders in cattle, replacing exploratory laparotomy [5]. As it is a non-invasive procedure, which does not require anesthetic containment, is painless and non-toxic, and is a precise technique, ultrasonography has been widely used in the clinical routine of ruminants [7]. Laparotomy should be avoided in cases with a poor prognosis, as in addition to the cost, it entails unnecessary stress and makes slaughter and consumption unfeasible for some time after surgery $[4,5]$.

The cross-sectional image of the small bowel segment, similar to multiple concentric rings ("onion rings", "target pattern", or "bull's eye") was also 
described, as the main finding, both by the transabdominal [21,25] and transrectal technique [14,17], in studies that reported cases of intussusception in cattle in other countries. The variation in the echogenicity of the rings corresponds to the degree of edema in the intestinal wall, due to the circulatory impairment of the affected segment $[5,13]$.

The presence of multiple dilated small bowel loops, filled with hypoechoic content and with hypermotility is also a frequent finding in cases of intestinal obstruction. This occurs due to the accumulation of fluids and ingest in the lumen of the segments proximal to the obstruction $[13,14,25]$. In addition, the presence of anechoic content between the dilated bowel loops can be attributed to transudation, due to increased intestinal permeability, and may be indicative of peritonitis. [4].

The ultrasonographic findings were essential for closing the diagnosis of intussusception, but the seriousness of the clinical condition made it impossible to treat the animal, confirming the importance of early diagnosis [22].

The anatomopathological findings, similar to those described by other authors [2,13,19,21], denote the severity of this type of obstruction and confirm the small intestine as the segment most involved in cases of intussusception in this species [8].

Intussusception must be considered as a cause of intestinal obstruction in calves and delayed diagnosis of this disease may make its treatment unfeasible. Ultrasound examination was essential for the diagnosis. Although, in this case, the ultrasound images were characteristic of intussusception, in many cases it is not possible to obtain images of the lesion site due to its medial position and the distension of the oral segments to the obstruction that occupy a large part of the abdominal cavity. It is noteworthy that in cases where it is not possible to obtain images of the obstructed segment, the finding of distension of intestinal segments should be interpreted as an obstructive process, although it is not possible to identify the cause [3].

Other ultrasound findings, such as increased peritoneal fluid and deposition of inflammatory material (fibrin) in the serosa of the loops and in the peritoneum, adhering to these segments, make this tool essential not only for diagnosis, but for establishing the prognosis of cases of intestinal affections [5].

For all these aspects, the use of ultrasonography as a diagnostic tool in cattle should be enhanced, aiming at the early determination of diagnosis and prognosis, thus reducing producer costs and animal discomfort.

\section{MANUFACTURER}

${ }^{1}$ Mindray Bio-Medical Electronics Co. Ltd. Shenzhen, China.

Declaration of interest. The authors report no conflicts of interest. The authors alone are responsible for the content and writing of the paper.

\section{REFERENCES}

1 Afonso J.A.B. 2017. Afecções intestinais em bovinos. Revista Acadêmica: Ciência Animal. 15(Suppl 2): 15-20.

2 Afonso J.A.B. \& Costa N.A. 2007. Obstrução intestinal em bovinos, In: Riet-Correa F., Schild A.L., Lemos R.A.A. \& J.R. Borges (Eds). Doenças Ruminantes e Equídeos. 3.ed. São Paulo: Livraria Varela, pp.369-373.

3 Anderson D.E. \& Ewoldt J.M.I. 2005. Intestinal surgery of adult cattle. Veterinary Clinics of North America - Food Animal Practice. 21(1): 133-154.

4 Braun U. 2003. Ultrasonography in gastrointestinal disease in cattle. Veterinary Journal. 166(2): 112-124.

5 Braun U. 2005. Ultrasound as a decision-making tool in abdominal surgery in cows. Veterinary Clinics of North America - Food Animal Practice. 21(1): 33-53.

6 Braun U. \& Götz M. 1994. Ultrasonography of the reticulum in cows. American Journal of Veterinary Research. 55(3): 325-332.

7 Cajueiro J.F.D.P. 2018. Ultrassonografia aplicada à clínica de ruminantes. In: Proceedings of the 5th Week of Veterinary Medicine at the Federal University of Alagoas. (Viçosa, Alagoas). [Fonte: < https://www.seer.ufal.br/index.php/ medvet/article/view/5951/4327>]

8 Constable P.D., St Jean G., Hull B.L., Rings D.M., Morin D.E. \& Nelson D.R. 1997. Intussusception in cattle: 336 cases (1964-1993). Journal of the American Veterinary Medical Association. 210(4): 531-536.

9 Desrochers A. \& Anderson D.E. 2016. Intestinal Surgery. Veterinary Clinics of North America - Food Animal Practice. 32(3): 645-671. 
10 Dirksen G. 1993. Sistema Digestivo. In: G. Dirksen, H.D. Günder \& M. Stöber (Eds). Rosenberger Exame Clínico Dos Bovinos. 3.ed. Rio de Janeiro: Guanabara Koogan, pp.163-224.

11 Guard C.L. \& Francoz D. 2015. Obstructive Intestinal Diseases. In: B. Smith (Ed). Large Animal Internal Medicine. 5th edn. St. Louis: Mosby, pp.820-824.

12 Harvey J.W. 2012. Hematology procedures. In: Harvey J.W. (Ed). Veterinary Hematology A Diagnostic Guide Color Atlas. St. Louis: Elsevier, pp.11-32.

13 Imran S., Tyagi S.P., Kumar A., Kumar A., Sharma A. \& Sharma S. 2011. Usefulness and limitation of ultrasonography in the diagnosis of intestinal intussusception in Cows. Veterinary Medicine International. 2011: 10-15.

14 Karapinar T. \& Kom M. 2007. Transrectal ultrasonographic diagnosis of jejunoileal intussusception in a cow. Irish Veterinary Journal. 60(7): 422-424.

15 Khalphallah A., Aref N.E.M., Elmeligy E. \& El-Hawari S.F. 2016. Clinical and ultrasonographic observations of functional and mechanical intestinal obstruction in buffaloes (Bubalus bubalis). Veterinary World. 9(5): 475-480.

16 Luna S.P.L. \& Teixeira M.W. 2007. Eutanásia: considerações éticas e indicações técnicas. Revista CFMV. 13(41): 60-69.

17 Mann J.S., Kumar A., Bharadwaj H. \& Nashiruddullah N. 2019. Clinicophysiological, Ultrasonographic and Histopathological Evaluation of 30 Cases in Cattle Suffering from Small Bowel Intussusception. International Journal of Current Microbiology and Applied Sciences. 8(08): 647-665.

18 Marques A.L.A., Aguiar G.M.N., Lira M.A.A., Miranda Neto E.G., Azevedo S.S. \& Simões S.V.D. 2018. Digestive diseases of cattle from the semiarid of Brazil. Pesquisa Veterinária Brasileira. 38(3): 407-416.

19 Marques L.C., Cattelan J.W., Macoris D.G., Marques J.A., Portugal E.S. \& Cadioli F.A. 2001. Estudo clínico, cirúrgico e anatomopatológico de intussuscepção em quatro bovinos. Arquivo Brasileiro de Medicina Veterinária e Zootecnia. 53(1): 52-57.

20 Pearson H. 1971. Intussusception in cattle. Veterinary Record. 89(16): 426-437.

21 Pravettoni D., Morandi N., Rondena M., Riccaboni P., Zani D.D., Scandella M. \& Belloli A.G. 2009. Repeated occurrence of jejuno-jejunal intussusception in a calf. Canadian Veterinary Journal. 50(3): 287-290.

22 Silva Filho A.P., Afonso J.A.B., Souza J.C.A., Costa N.A. \& Mendonça C.L. 2010. Análise clínica e patológica em 20 casos de intussuscepção em bovinos. Veterinária e Zootecnia. 17(3): 421-430.

23 Soares G.S., Costa N.A., Afonso J.A.B., Souza M.I., Cajueiro J.F.P., Silva J.C.R., Ferreira F. \& Mendonça C.L. 2021. Digestive diseases of cattle diagnosed at the "Clínica de Bovinos de Garanhuns " - UFRPE: retrospective study and influence of seasonality. Pesquisa Veterinária Brasileira. 41(e06800).

24 Streeter R.N. \& Step D.L. 2007. Diagnostic Ultrasonography in Ruminants. Veterinary Clinics of North America: Food Animal Practice. 23(3): 541-574.

25 Venkatesan M., Saravanan M., Selvaraj P., Yogeshpriya S., Jayalakshmi K. \& Veeraselvam M. 2018. Transabdominal Ultrasonographic studies in Jejunal, Ileal and Caecal disorder of Cows and Bulls. International Journal of Microbiology Research. 10(8): 6-9. 